\title{
Effectiveness of Remission Induction Strategies for Early Rheumatoid Arthritis: a Systematic Literature Review
}

\author{
M. M. A. Verhoeven ${ }^{1}$ • P. M. J. Welsing ${ }^{1}$ • J. W. J. Bijlsma ${ }^{1} \cdot$ J. M. van Laar ${ }^{1}$ • F. P. J. G. Lafeber ${ }^{1} \cdot$ J. $^{\text {Tekstra }^{1}}$ • \\ J. W. G. Jacobs ${ }^{1}$
}

Published online: 23 April 2019

(C) The Author(s) 2019

\begin{abstract}
Purpose of Review To review the effectiveness of remission induction strategies compared to single csDMARD-initiating strategies according to current guidelines in early RA.

Recent Findings Twenty-nine studies, heterogeneous on, e.g., specific treatment strategy and remission outcome used, were identified. Using DAS28-remission over 12 months, 13 (76\%) of 17 remission induction strategies showed significantly more patients achieving remission. Pooled relative "risk" was 1.73 [95\% CI 1.59-1.88] for bDMARD-based remission induction strategies and 1.20 [95\%CI 1.03-1.40] for combination csDMARD-based remission induction strategies compared to single csDMARD-initiating strategies. When additional glucocorticoid "bridging therapy" was used in single csDMARD-initiating strategies, the higher proportion patients achieving remission in remission induction strategies was no longer statistically significant (pooled RR 1.06 [95\%CI 0.83-1.35]). For other remission outcomes, results were in line with above.

Summary Remission induction strategies are more effective in achieving remission compared to single csDMARD-initiating strategies, possibly more so in bDMARD-based induction strategies. However, compared to single csDMARD-initiating strategies with glucocorticoids, induction strategies may not be more effective.
\end{abstract}

Keywords Early rheumatoid arthritis $\cdot$ Induction therapy $\cdot$ Standard care $\cdot$ bDMARDs $\cdot$ csDMARDs $\cdot$ GCs

\section{Introduction}

In rheumatoid arthritis (RA), early initiation of diseasemodifying anti-rheumatic drug (DMARD) treatment, preferably within the "window of opportunity," is thought to optimally prevent joint damage, improving long-term outcome and quality of life $[1,2]$.

Accordingly, current international guidelines advice to start treatment in early RA as soon as possible after diagnosis. Initial therapy is started with a conventional synthetic (cs)DMARD, most frequently methotrexate (MTX), in a

This article is part of the Topical Collection on Rheumatoid Arthritis

Electronic supplementary material The online version of this article (https://doi.org/10.1007/s11926-019-0821-1) contains supplementary material, which is available to authorized users.

M. M. A. Verhoeven

m.m.a.verhoeven-15@umcutrecht.nl

1 Department of Rheumatology \& Clinical Immunology, University Medical Center Utrecht, Utrecht University, G02.228, P.O. Box 85500, 3508GA Utrecht, The Netherlands "tight-controlled" manner, aiming for low disease activity or, preferably, remission $[1,3]$.

Initial MTX therapy is sometimes combined with shortterm use of moderate-high dose glucocorticoids (GCs), which are then tapered as soon as possible: GC bridging therapy. The treatment strategy has to be intensified if the treatment target is not achieved within 6 months $[1,3]$. This next step is often to add a biological (b) or targeted small molecule (ts) DMARD $[4 \cdot \bullet, 5]$.

Previous research shows that approximately $30-50 \%$ of early RA patients need additional b/tsDMARD therapy [6].

Patients who initiate a more intensive DMARD strategy as first-line treatment than that according to current guidelines as described above have sometimes shown superior effectiveness outcomes, and achieve remission more often and earlier, sometimes also including sustained remission (SR) and even sustained drug-free remission (sDFR), which may thus become achievable treatment targets $[4 \bullet \bullet, 7]$.

Achieving remission earlier has been found to be related to improved long-term outcomes [7].

Furthermore, SR and sDFR may become future treatment targets for early RA within the window of opportunity. This 
may lead to a paradigm shift towards the above described so called remission induction strategies.

For this reason, it would be interesting to investigate the effectiveness of initiating in early RA more intensive treatment strategies, compared to single csDMARD-initiating strategies according to current guidelines; these more intensive strategies herein are designated remission induction strategies.

The aim of the study is to provide a systematic summary of these remission induction strategies and their effectiveness.

\section{Methods}

\section{Systematic Literature Search and Study Selection}

A systematic review of the literature was performed according to current standards and reported according to the Preferred Items for Systematic Reviews and Meta-analyses (PRISMA) statement protocol [8]. In October 2018, we performed a literature search in Medline and Embase. The search combined terms relating to early RA, terms for cs-, b-, and tsDMARD and remission, and publications limited to the last 5 years and English language. More details about the research question and search terms can be found in the Supplementary file.

We defined more intensive, remission induction strategies as initiating treatment with a bDMARD or a tsDMARD, both with and without a csDMARD, or initiating a csDMARD with moderately or high-dosed GCs, with delayed tapering (not "bridging therapy") or starting $\geq 2$ csDMARDs.

The single csDMARD-initiating strategy was defined as starting treatment with a single csDMARD, with or without GCs as bridging therapy, according to the current guidelines.

All titles and abstracts were screened by MMAV. If the reviewer was unsure about in-/excluding an abstract, it was discussed with one other co-author (PMJW) and one coinvestigator $(\mathrm{MdH})$ to reach consensus, and in case of remaining doubt based on title/abstract, the publication was included for full text evaluation. Full text screening was performed using the same strategy.

The following selection criteria were used: (1) human studies, (2) (very, DMARD-naive) early RA patients, (3) remission induction strategy arm (according to definition of remission induction strategy, see above), (4) single csDMARDinitiating strategy arm (according to definition of single csDMARD-initiating strategy, see above) and, (5) results presented regarding the comparison of a remission induction strategy and a single csDMARD-initiating strategy on an outcome of remission.

Remission was defined as remission according to a validated disease activity index or the Boolean definition [1].

Randomized controlled trials (RCTs) as well as cohort studies with appropriate correction for multiple confounders were selected. Long-term extension studies of trials satisfying the above criteria were also selected to investigate long-term effects of remission induction strategies on, e.g., radiographic progression.

\section{Data Extraction and Outcome Assessment}

The following data of studies was extracted: publication year, study design, patients' baseline characteristics (age, gender, rheumatoid factor (RF) status, Health Assessment Questionnaire (HAQ), symptom duration, Disease Activity Score assessing 28 joints (DAS28), a description of the single csDMARD-initiating strategy and the remission induction strategy, the number of patients per arm, a description of the remission outcome, the number of patients achieving remission per arm, a description of missing data, and other remarks deemed necessary. In case of a study evaluating long-term outcomes of a remission induction strategy, we extracted additional information (if available) for the follow-up duration, outcome for disease activity, medication use and radiographic progression.

A quality assessment of all selected publications was performed using "The Cochrane Collaboration's tool for assessing risk of bias" [9]. Information about random sequence generation, allocation concealment, blinding of participants and personnel, blinding of outcome assessment, incomplete outcome assessment, and selective reporting was evaluated.

\section{Statistics}

Relative risks (RR) for achieving remission with $95 \%$ confidence intervals $(\mathrm{CI})$ per study were calculated, separate for each remission outcome definition and graphically displayed in forest plots. When appropriate, results were pooled using a random-effect model according to the Mantel-Haenszel method. To explore the effects of specific remission induction strategy used (e.g., use of a b/tsDMARD, the use of GC bridging therapy in the single csDMARD-initiating strategy) and the effect of symptom duration at start of therapy (within the window of opportunity, arbitrarily defined as symptom duration $\leq$ 3 months, versus outside the window of opportunity, arbitrarily defined as symptom duration $>3$ months) [2], group analyses were performed.

Outcomes of studies evaluating the longer term effectiveness of remission induction strategies were only summarized descriptively.

All analyses were performed in Review manager version $5.3[10]$.

\section{Results}

After screening, 23 articles and 6 conference abstracts were included, involving 6319 patients treated according to a remission induction strategy and 4647 according to a single 
csDMARD-initiating strategy (see flowcharts in Supplementary figure 1). Four specific groups were defined based on characteristics of the drug regime and study duration, and comparisons made: (1) b/tsDMARD-based remission induction strategy versus single csDMARD-initiating strategy without GC bridging, (2) combination csDMARD-based remission induction strategy versus single csDMARD-initiating strategy without GC bridging, (3) remission induction strategy (either combination csDMARD-based strategy or bDMARDbased strategy) versus single csDMARD-initiating strategy with GC bridging, and (4) studies evaluating long-term effects of remission induction strategies (follow-up $>4$ years). An overview of patient and study characteristics of the included studies is shown in Table 1.

Several of the 29 studies used more than 1 remission definition; in all, 46 remission definitions were used, range 1-4 per study. Most studies used at least a definition of remission where remission had to be present $\geq 1$ visit within 6 to 12 months follow-up and according to one of our remission outcome definitions; we will describe the results based on these outcomes (Table 1). Seventeen studies defined remission as DAS28<2.6, 12 studies used the Boolean remission definition, 7 studies used $\mathrm{CDAI} \leq 2.8$, and 10 studies used $\mathrm{SDAI} \leq 3.3$; results are described separately below. Overall, for 32 of the 46 remission definitions (70\%), a statistically significant effect in favor of remission induction strategy was found.

\section{DAS28-Based Remission}

When DAS28 was used for remission definition, 13/17 (76\%) studies showed a statistically significant effect in favor of the remission induction strategy (Fig. 1). The pooled RR of achieving remission for strategies using a bDMARD in the remission induction strategy compared to the single csDMARD-initiating strategy without GC bridging was 1.73 [95\%CI $1.59-1.88$ ] versus 1.20 [95\% CI 1.03-1.40] for studies which used a combination csDMARD-based remission induction strategy compared to the single csDMARD-initiating strategy without GC bridging. For studies using $\mathrm{GC}$ bridging in the single csDMARD-initiating strategy, no statistically significant additional effect for the remission induction strategy was found (pooled RR 1.06 [95\% CI 0.83-1.35]). One of them used a bDMARD in the remission induction strategy arm. [29] One cohort study only provided an OR for achieving remission in patients treated with a remission induction strategy compared to a single csDMARDinitiating strategy, with or without additional GC use (without sufficient information to calculate an RR). Results were in favor of the remission induction strategy (OR 1.82 [95\%CI 1.01-3.29]) [25].

\section{Boolean-Based Remission}

For Boolean remission, 5/12 (42\%) studies showed a statistically significant effect in favor of the remission induction strategy. The pooled RR of achieving Boolean remission for the bDMARD-based remission induction strategy compared to the single csDMARD-initiating strategy without GC bridging was 1.75 [95\%CI 1.40-2.20], versus 0.79 [95\% CI $0.58-$ 1.07] for the remission induction strategy (1/5 bDMARD use in the remission induction strategy) [29] compared to the single csDMARD-initiating strategy with GC bridging (Fig. 2).

\section{CDAl-Based Remission}

Only studies with $\mathrm{b} / \mathrm{tsDMARD}$ use in the remission induction strategy versus single csDMARD-initiating strategy without GC bridging were included in the analysis for CDAI remission. All studies $(7 / 7,100 \%)$ showed a statistical significant effect in favor of the remission induction strategy arm. The pooled RR of achieving CDAI remission was $1.68[95 \% \mathrm{CI}$ 1.46-1.92] (Fig. 3).

\section{SDAI-Based Remission}

Nine studies with bDMARD use in the remission induction strategy arm versus single csDMARD-initiating strategy without GC bridging, and one study using a bDMARD-based remission induction strategy versus a single csDMARDinitiating strategy with GC bridging were included in the analysis for SDAI remission [29]. A significant effect in favor of the remission induction strategy was found in $7 / 10(70 \%)$ studies (Fig. 4). The pooled RR of achieving SDAI remission was 1.66 [95\%CI 1.44-1.90] for bDMARD use in the remission induction strategy arm versus the single csDMARDinitiating strategy without GC bridging arm. And for the single study where a remission induction strategy was compared to a single csDMARD-initiating strategy with GC bridging, this was 1.10 [95\%CI 0.60-2.05].

\section{Symptom Duration}

Regarding symptom duration, six studies started treatment "within the window of opportunity" (symptom duration $\leq$ 3 months). Another nine studies started treatment "outside the window of opportunity" (symptom duration > 3 months; range 4-10 months). All studies reported the DAS28-based remission outcome, and 11/15 (73\%) showed a statistically significant effect in favor of the remission induction strategy. The pooled RR of achieving remission for strategies within the window of opportunity was 1.43 [95\%CI 1.15-1.77] versus 1.44 [95\%CI 1.12-1.86] for studies outside the window of opportunity. Five studies used a single csDMARD-initiating 


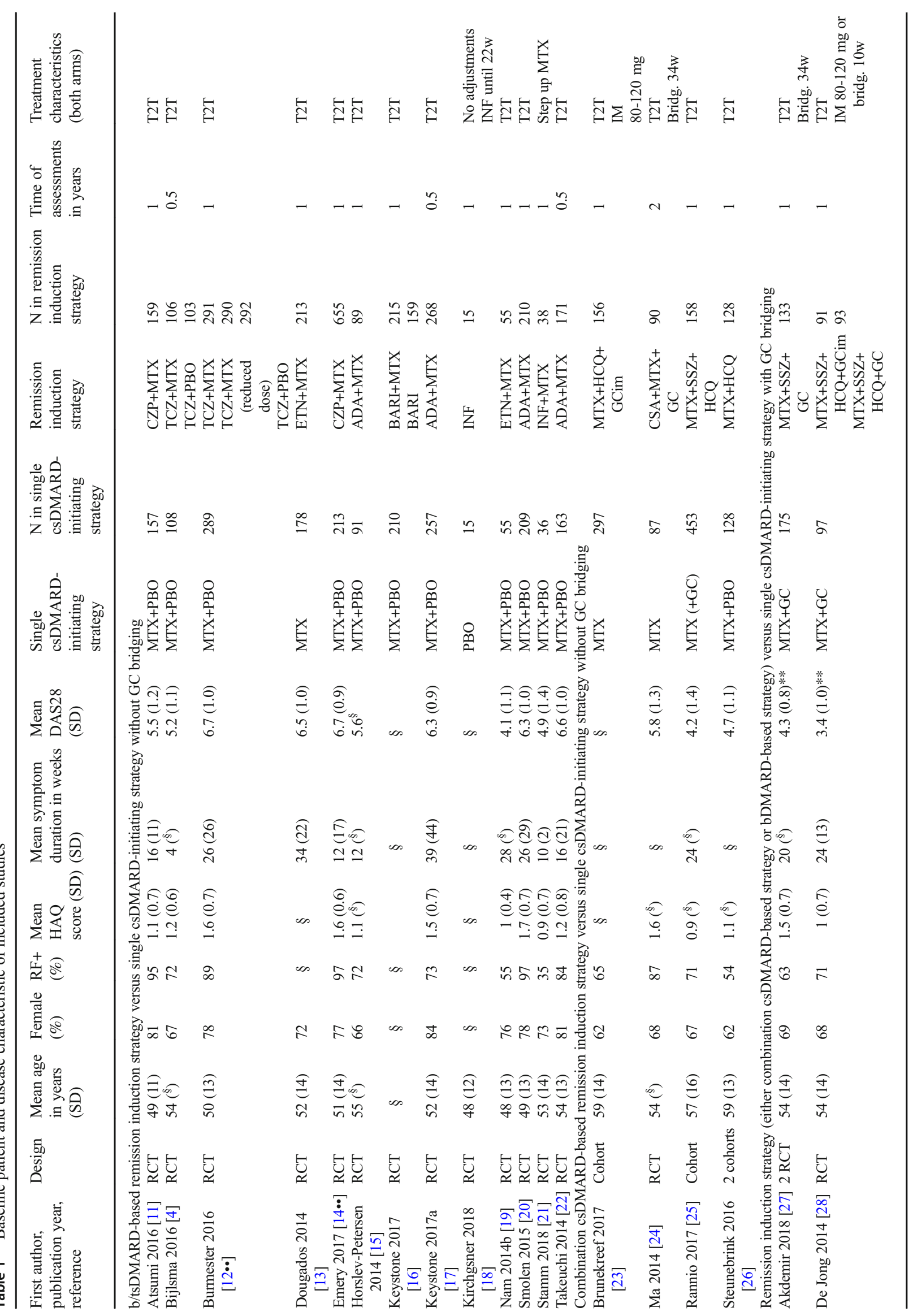




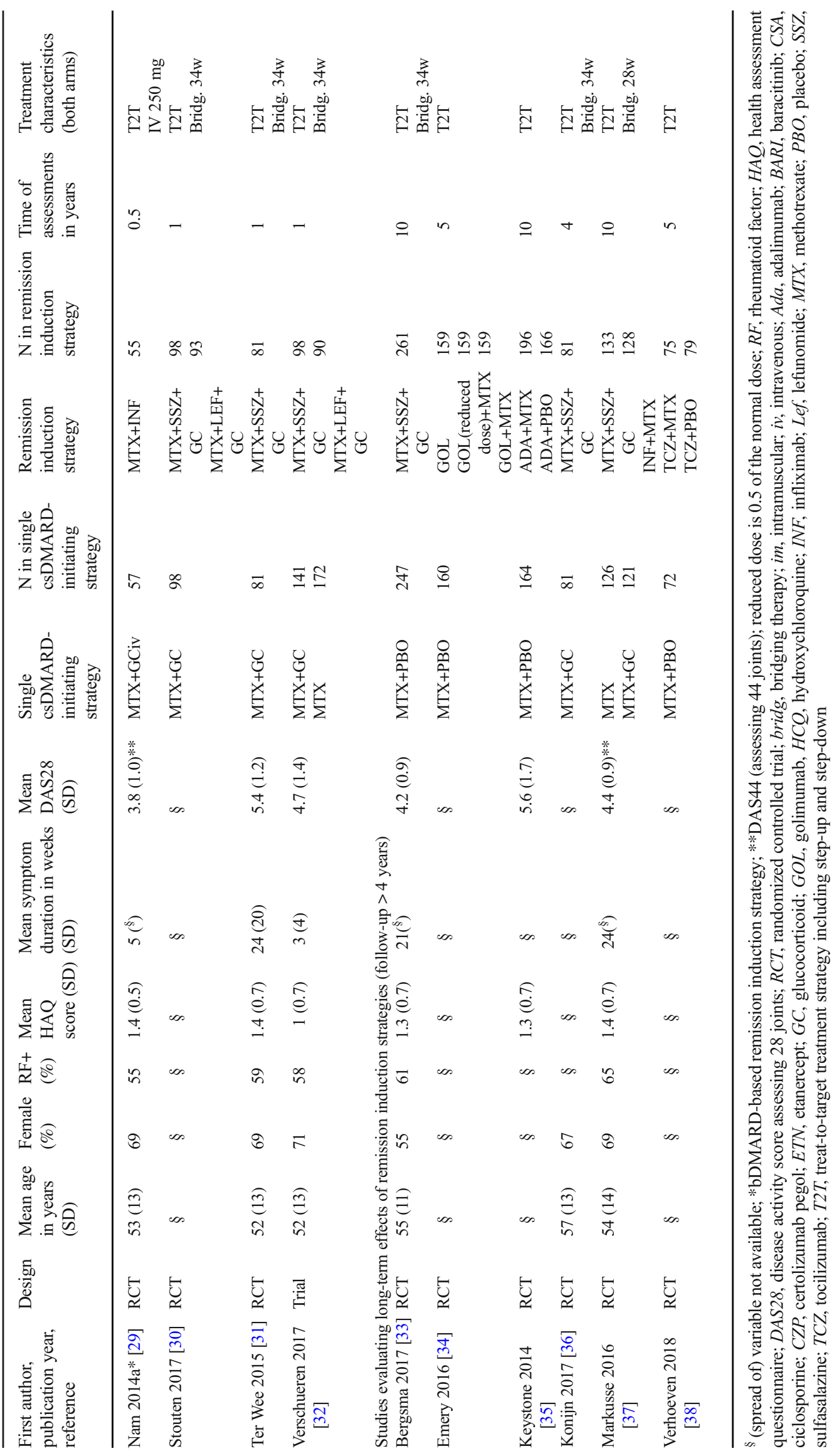




\begin{tabular}{|c|c|c|c|c|c|c|c|c|c|}
\hline \multirow[b]{2}{*}{ Study } & \multicolumn{2}{|c|}{ Induction } & \multicolumn{2}{|c|}{ CSDMARD } & \multicolumn{2}{|r|}{ Risk Ratio } & \multirow{2}{*}{\multicolumn{2}{|c|}{$\begin{array}{l}\text { Risk Ratio } \\
\text { M-H, Random, 95\% Cl }\end{array}$}} & \\
\hline & Events & Total & Events & Total & Weight & $\mathrm{M}-\mathrm{H}, \mathrm{Random}, 95 \% \mathrm{Cl}$ & & & \\
\hline \multicolumn{8}{|c|}{ bDMARD based remission-induction strategy versus single csDMARD-initiating strategy without GC bridging } & & \\
\hline Atsumi 2016 & 91 & 159 & 58 & 157 & $12.0 \%$ & $1.55[1.21,1.98]$ & & & \\
\hline Bijlsma 2016 & 161 & 207 & 42 & 106 & $11.9 \%$ & $1.96[1.53,2.51]$ & & $\square$ & \\
\hline Burmester 2016 & 355 & 870 & 56 & 287 & $11.7 \%$ & $2.09[1.63,2.68]$ & & $\square$ & \\
\hline Dougados 2014 & 119 & 212 & 64 & 176 & $13.7 \%$ & $1.54[1.23,1.94]$ & & & \\
\hline Emery 2017 & 279 & 655 & 57 & 213 & $12.6 \%$ & $1.59[1.25,2.02]$ & & & \\
\hline Horslev-Petersen 2014 & 66 & 89 & 45 & 91 & $12.4 \%$ & $1.50[1.18,1.91]$ & & - & \\
\hline Keystone $2017 a$ & 98 & 267 & 48 & 252 & $8.0 \%$ & $1.93[1.43,2.60]$ & & & \\
\hline Kirchgesner 2018 & 5 & 10 & 3 & 10 & $0.6 \%$ & $1.67[0.54,5.17]$ & & & \\
\hline Smolen 2015 & 100 & 210 & 57 & 209 & $10.4 \%$ & $1.75[1.34,2.27]$ & & 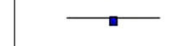 & \\
\hline Stamm 2018 & 24 & 38 & 13 & 36 & $2.9 \%$ & $1.75[1.06,2.88]$ & & & \\
\hline Takeuchi 2014 & 53 & 171 & 24 & 163 & $3.9 \%$ & $2.11[1.37,3.24]$ & & & \\
\hline Subtotal $(95 \% \mathrm{Cl})$ & & 2888 & & 1700 & $100.0 \%$ & $1.73[1.59,1.88]$ & & & \\
\hline \multicolumn{9}{|l|}{ Heterogeneity: $\left.\right|^{2}=0 \%$} & \\
\hline \multicolumn{10}{|c|}{$\begin{array}{l}\text { Combination CSDMARD based remission-induction strategy versus single csDMARD-initiating strategy without } \\
\text { GC bridging }\end{array}$} \\
\hline Brunekreef 2017 & 138 & 156 & 214 & 297 & $51.6 \%$ & $1.23[1.12,1.34]$ & & & \\
\hline Ma 2014 & 30 & 90 & 16 & 87 & $7.6 \%$ & $1.81[1.07,3.08]$ & & & \\
\hline Steunebrink 2016 & 99 & 128 & 92 & 128 & $40.9 \%$ & $1.08[0.93,1.24]$ & & & \\
\hline Subtotal $(95 \% \mathrm{Cl})$ & & 374 & & 512 & $100.0 \%$ & $1.20[1.03,1.40]$ & & & \\
\hline Total events & 267 & & 322 & & & & & & \\
\hline \multicolumn{10}{|l|}{ Heterogeneity: $\left.\right|^{2}=59 \%$} \\
\hline \multicolumn{10}{|c|}{ Remission-induction strategy versus single csDMARD-initiating strategy with GC bridging } \\
\hline Nam 2014a* & 22 & 59 & 29 & 57 & $20.4 \%$ & $0.73[0.48,1.11]$ & 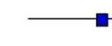 & & \\
\hline Stouten 2017 & 121 & 191 & 59 & 98 & $37.5 \%$ & $1.05[0.87,1.28]$ & & & \\
\hline Verschueren 2017 & 121 & 156 & 115 & 188 & $42.0 \%$ & $1.27[1.10,1.46]$ & & & \\
\hline Subtotal $(95 \% \mathrm{Cl})$ & & 406 & & 343 & $100.0 \%$ & $1.06[0.83,1.35]$ & & & \\
\hline Total events & 264 & & 203 & & & & & & \\
\hline \multicolumn{10}{|l|}{ Heterogeneity: $\left.\right|^{2}=73 \%$} \\
\hline & & & & & & 0.2 & 0.5 & 2 & 5 \\
\hline
\end{tabular}

Fig. 1 Forest plot of DAS28 remission outcome in individual studies comparing remission induction strategies with single csDMARDinitiating strategies. DAS28 remission, DAS28 < 2.6; induction, remission

strategy with GC bridging (i.e., two studies within and three studies outside; Supplementary figure 2).

\section{Longer Term Effectiveness of Remission Induction Strategies Started in Early RA}

We found six studies evaluating the effect of a remission induction strategy versus a single csDMARD-initiating strategy on the long term (4 to 10 years). In four studies, DAS remission was more often achieved in the initial remission induction strategy compared to the single csDMARD-initiating strategy over time [33-35, 37]. In the remission induction strategy arm, Boolean remission, as well as SDAI remission, was less often achieved in one of two studies with no difference in the other, compared to induction strategy arm; csDMARD, single csDMARD-initiating strategy arm; M-H, Mantel-Haenszel; Random, random effect; *bDMARD-based remission induction strategy. $95 \% \mathrm{CI}, 95 \%$ confidence interval

the single csDMARD-initiating strategy arm [34, 36]. No difference was found for CDAI remission, which was reported in only one study [34]. One study reported data about SR, which was achieved in almost all patients over time, without differences between the different strategy arms [38]. However, using (s)DFR as outcome, differences were shown in favor of the remission induction strategies [37, 38]. No differences were found for radiographic progression over time between the different strategies [33-35, 37]. Details of these studies can be found in Table 1.

\section{Risk of Bias Assessment}

The risk of bias of the included studies was overall low. In general, 26/29 studies were RCTs, the remaining 3 


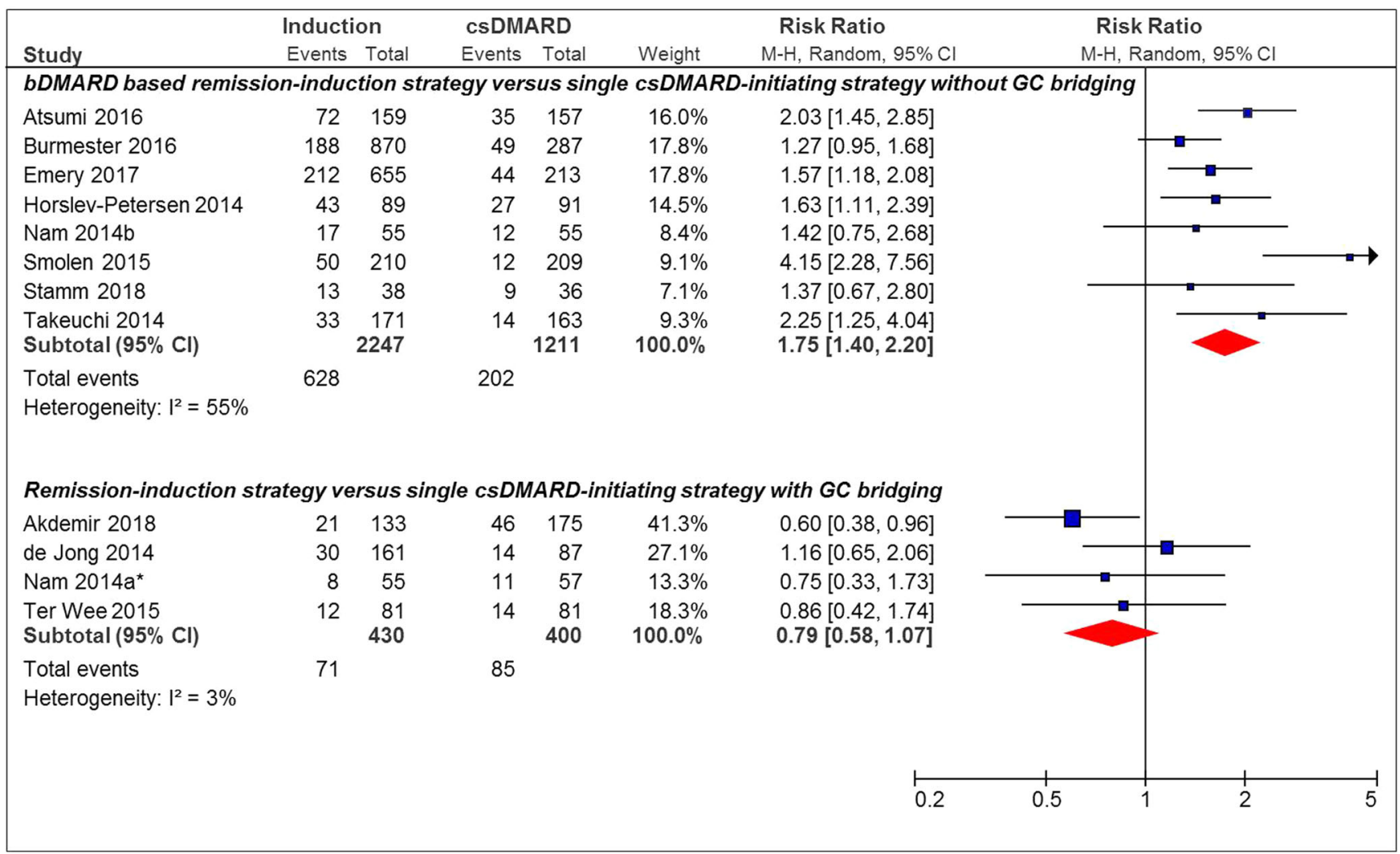

Fig. 2 Forest plot of Boolean remission outcome in individual studies comparing remission induction strategies with single csDMARDinitiating strategies. Boolean remission - tender joint count $\leq 1$, swollen joint count $\leq 1, \mathrm{CRP} \leq 1 \mathrm{mg} / \mathrm{dL}$, patient global assessment $\leq 1$ (on a $0-10$

were cohort studies. An overview of the risk of bias assessment is shown in Supplementary table 1. In the studies evaluating long-term effects of a remission induction strategy, after the initial RCT [33-38], treatment was according to the treating physician and standard care, without detailed information on the initial trial and attrition, prohibiting to fully assess all items of the risk of bias assessment. Further, moderate/high risk of bias was present in the seven studies evaluating short-term effects [23, 25-27, 30-32].

\section{Discussion}

The current meta-analysis shows that a remission induction strategy is more effective compared to a single csDMARD-initiating strategy, possible specifically for bDMARD-based remission induction strategies. However, this superior effect over single csDMARDinitiating strategy is limited and is not statistically significant, if patients are treated initially also with GCs, shortterm as "bridging therapy." Longer term follow-up studies showed conflicting results, but a more favorable outcome scale); induction, remission induction strategy arm; csDMARD, single csDMARD-initiating strategy arm; M-H, Mantel-Haenszel; random, random effect; *bDMARD-based remission induction strategy. 95\% CI, $95 \%$ confidence interval

with regard to (s)DFR for the remission induction strategy may be present.

No overall pooled effect estimate was given as studies were highly heterogeneous in study design regarding, e.g., specific drug regimen and remission outcome used. We therefore defined groups of more homogeneous studies based on specific remission outcomes and characteristics of drug regimen. Results within these groups show that heterogeneity is typically low, and therefore we pooled the effect estimates. However, in some of these groups, heterogeneity was moderate, based on differences in study design, medical treatment, risk of bias and/or patient characteristics $\left(\mathrm{I}^{2}>50 \%\right.$, see Figs. 1 and 2$)$.

One surprising finding was that the added value of a remission induction strategy was found to be limited and nonstatistically significant when compared to a single csDMARDinitiating strategy with GC bridging therapy. This may suggest that the current early start of therapy, including a treat to target approach with swift step-up treatment adjustments, achieves already very good results when the initial delay in treatment effect is covered by the bridging therapy.

Contrary to expectation, similar beneficial outcomes for patients treated within the window of opportunity were found when compared with those for patients treated outside the window of opportunity. However, only a limited number of studies reported 


\begin{tabular}{|c|c|c|c|c|c|c|c|c|c|}
\hline \multirow[b]{2}{*}{ Study } & \multicolumn{2}{|c|}{ Induction } & \multicolumn{2}{|c|}{ CsDMARD } & \multirow[b]{2}{*}{ Weight } & \multirow{2}{*}{$\begin{array}{c}\text { Risk Ratio } \\
\mathrm{M}-\mathrm{H}, \text { Random, } 95 \% \mathrm{Cl}\end{array}$} & \multirow{2}{*}{\multicolumn{2}{|c|}{$\begin{array}{c}\text { Risk Ratio } \\
\mathrm{M}-\mathrm{H}, \text { Random, } 95 \% \mathrm{Cl}\end{array}$}} & \\
\hline & Events & Total & Events & Total & & & & & \\
\hline \multicolumn{8}{|c|}{ b/tsDMARD based remission-induction strategy versus single csDMARD-initiating strategy without GC bridging } & & \\
\hline Bijlsma 2016 & 57 & 207 & 13 & 106 & $5.6 \%$ & $2.25[1.29,3.91]$ & & & \\
\hline Burmester 2016 & 241 & 870 & 57 & 287 & $19.8 \%$ & $1.39[1.08,1.80]$ & & & \\
\hline Emery 2017 & 255 & 655 & 56 & 213 & $21.1 \%$ & $1.48[1.16,1.89]$ & & & \\
\hline Horslev-Petersen 2014 & 54 & 89 & 37 & 91 & $15.8 \%$ & $1.49[1.11,2.01]$ & & & \\
\hline Keystone 2017 & 185 & 374 & 53 & 210 & $19.9 \%$ & $1.96[1.52,2.53]$ & & & \\
\hline Smolen 2015 & 72 & 210 & 34 & 209 & $11.8 \%$ & $2.11[1.47,3.02]$ & & & \\
\hline $\begin{array}{l}\text { Takeuchi } 2014 \\
\text { Subtotal }(95 \% \mathrm{Cl})\end{array}$ & 35 & $\begin{array}{r}171 \\
2576\end{array}$ & 18 & $\begin{array}{r}163 \\
1279\end{array}$ & $\begin{array}{r}6.1 \% \\
100.0 \%\end{array}$ & $\begin{array}{r}1.85[1.09,3.14] \\
1.68[1.46,1.92]\end{array}$ & & & \\
\hline \multirow[t]{2}{*}{$\begin{array}{l}\text { Total events } \\
\text { Heterogeneity: }\left.\right|^{2}=23 \%\end{array}$} & 899 & & 268 & & & & & & \\
\hline & & & & & & 0.2 & 0.5 & 1 & 5 \\
\hline
\end{tabular}

Fig. 3 Forest plot of CDAI remission outcome in individual studies comparing remission induction strategies with single csDMARDinitiating strategies. CDAI remission, $\mathrm{CDAI} \leq 2.8$; induction, remission

data on symptom duration which is notoriously difficult to define, and our study was not specifically designed to test the window of opportunity hypothesis. Outside of our study, in some papers, a difference in effectiveness of treatment has been shown in favor of patients treated within the window of opportunity [2, 39].

In general, long-term effectiveness outcomes were not different between a remission induction strategy and a single csDMARD-initiating strategy probably due to the widely applied treat to target principle [1].

Results of our systematic literature review are in line with an earlier performed systematic literature review, which induction strategy arm; csDMARD, single csDMARD-initiating strategy arm; M-H, Mantel-Haenszel; random, random effect. 95\% CI, 95\% confidence interval

included only remission induction strategies using a $\mathrm{b} /$ tsDMARD in the experimental arm [40]. We, uniquely include also combination csDMARD-based remission induction strategy arms, providing results applicable also for countries with limited availability of bDMARDs. Besides, we evaluated several established remission definitions according to validated disease activity indices and the Boolean definition [1].

No data on radiographic progression was reported, because of the limited study duration of most included studies; even over 2 years, radiographic progression is absent or modest at most in treat to target studies in early RA [41, 42]. Only some of the

\begin{tabular}{|c|c|c|c|c|c|c|c|c|c|}
\hline \multirow[b]{2}{*}{ Study } & \multicolumn{2}{|c|}{ Induction } & \multicolumn{2}{|c|}{ csDMARD } & \multicolumn{2}{|r|}{ Risk Ratio } & \multirow{2}{*}{\multicolumn{2}{|c|}{$\begin{array}{c}\text { Risk Ratio } \\
\mathrm{M}-\mathrm{H}, \text { Random, } 95 \% \mathrm{Cl} \\
\end{array}$}} & \\
\hline & Events & Total & Events & Total & Weight & $\mathrm{M}-\mathrm{H}$, Random, $95 \% \mathrm{Cl}$ & & & \\
\hline \multicolumn{8}{|c|}{ bDMARD based remission-induction strategy versus single csDMARD-initiating strategy without GC bridging } & & \\
\hline Atsumi 2016 & 77 & 159 & 53 & 157 & $17.9 \%$ & $1.43[1.09,1.88]$ & & & \\
\hline Dougados 2014 & 47 & 181 & 19 & 145 & $7.2 \%$ & $1.98[1.22,3.22]$ & & & \\
\hline Emery 2017 & 255 & 655 & 53 & 213 & $19.8 \%$ & $1.56[1.22,2.01]$ & & & \\
\hline Horslev-Petersen 2014 & 51 & 89 & 34 & 91 & $14.1 \%$ & $1.53[1.11,2.11]$ & & & \\
\hline Keystone $2017 a$ & 62 & 267 & 31 & 252 & $10.2 \%$ & $1.89[1.27,2.80]$ & & & \\
\hline Nam 2014b & 26 & 55 & 20 & 55 & $8.3 \%$ & $1.30[0.83,2.03]$ & & & \\
\hline Smolen 2015 & 70 & 210 & 26 & 209 & $9.7 \%$ & $2.68[1.78,4.03]$ & & & \\
\hline Stamm 2018 & 18 & 38 & 13 & 36 & $5.8 \%$ & $1.31[0.76,2.27]$ & & & \\
\hline $\begin{array}{l}\text { Takeuchi } 2014 \\
\text { Subtotal }(95 \% \mathrm{CI})\end{array}$ & 39 & $\begin{array}{r}171 \\
1825\end{array}$ & 20 & $\begin{array}{r}163 \\
1321\end{array}$ & $\begin{array}{r}7.0 \% \\
100.0 \%\end{array}$ & $\begin{array}{l}1.86[1.13,3.05] \\
1.66[1.44,1.90]\end{array}$ & & & \\
\hline $\begin{array}{l}\text { Total events } \\
\text { Heterogeneity: }\left.\right|^{2}=20 \%\end{array}$ & 645 & & 269 & & & & & & \\
\hline \multicolumn{10}{|c|}{ Remission-induction strategy versus single csDMARD-initiating strategy with GC bridging } \\
\hline $\begin{array}{l}\text { Nam } 2014 a^{\star} \\
\text { Subtotal }(95 \% \mathrm{Cl})\end{array}$ & 16 & $\begin{array}{l}59 \\
59\end{array}$ & 14 & $\begin{array}{l}57 \\
57\end{array}$ & $\begin{array}{l}100.0 \% \\
100.0 \%\end{array}$ & $\begin{array}{l}1.10[0.60,2.05] \\
1.10[0.60,2.05]\end{array}$ & & & \\
\hline \multirow[t]{2}{*}{ Total events } & 16 & & 14 & & & & & & \\
\hline & & & & & & 0.2 & 0.5 & 1 & 5 \\
\hline
\end{tabular}

Fig. 4 Forest plot of SDAI remission outcome in individual studies comparing remission induction strategies with single csDMARDinitiating strategies. SDAI remission, SDAI $\leq 3.3$; induction, remission induction strategy arm; csDMARD, single csDMARD-initiating strategy arm; M-H, Mantel-Haenszel; random, random effect; *bDMARD-based remission induction strategy 
long-term extension studies reported on radiographic progression, but did not show any statistically significant differences.

The majority of all included studies, i.e., 20/29 (69\%), were RCTs with no to moderate risk of bias. The longer term follow-up studies were follow ups of RCTs, in which the effectiveness was maintained, indicating the quality of keeping to the treat to target principle.

\section{Conclusions}

Remission induction strategies initiated in early RA patients are more effective in achieving remission compared to single csDMARD-initiating strategies. However, their benefit compared to that of a single csDMARD-initiating therapy strategy with GC bridging seems to be limited.

Acknowledgements We would like to thank M. de Hair (MdH) for her valuable input in this project during the initial phase.

\section{Compliance with Ethical Standards}

Conflict of Interest Dr. Lafeber reports grants from Roche, outside the submitted work.

Dr. Bijlsma reports grants from Pfizer, grants from Merck Sharp \& Dohme, grants from Bristol-Myers Squibb, grants from AbbVie, grants from Roche, outside the submitted work.

Dr. van Laar reports grants from Arthrogen, grants from MSD, personal fees from Pfizer, personal fees from Eli Lilly, personal fees from BMS, grants from Astra Zeneca, grants from Roche-Genentech, outside the submitted work.

M.M.A. Verhoeven, P.M.J. Welsing, J. Tekstra and J.W.G. Jacobs declare they have no conflicts to disclose.

Human and Animal Rights and Informed Consent This article does not contain any studies with human or animal subjects performed by any of the authors.

Open Access This article is distributed under the terms of the Creative Commons Attribution 4.0 International License (http:// creativecommons.org/licenses/by/4.0/), which permits unrestricted use, distribution, and reproduction in any medium, provided you give appropriate credit to the original author(s) and the source, provide a link to the Creative Commons license, and indicate if changes were made.

\section{References}

Papers of particular interest, published recently, have been highlighted as:

•• Of major importance

1. Smolen JS, Landewé R, Bijlsma J, Burmester G, Chatzidionysiou $\mathrm{K}$, Dougados M, et al. EULAR recommendations for the management of rheumatoid arthritis with synthetic and biological diseasemodifying antirheumatic drugs: 2016 update. Ann Rheum Dis. 2017;76:960-77.
2. Raza K, Filer A. The therapeutic window of opportunity in rheumatoid arthritis: does it ever close? Ann Rheum Dis. 2015;74:793-4.

3. Singh JA, Saag KG, Bridges SL, et al. 2015 American College of Rheumatology Guideline for the treatment of rheumatoid arthritis. Arthritis Rheumatol. 2016;68:1-26.

4.• Bijlsma JWJ, Welsing PMJ, Woodworth TG, et al. Early rheumatoid arthritis treated with tocilizumab, methotrexate, or their combination (U-Act-Early): a multicentre, randomised, double-blind, double-dummy, strategy trial. Lancet. 2016;388(10042):343-55 These studies are important because they were double-blind randomized controlled trials with a large sample size. The studies were powered to detect statistical significant differences. Besides, the articles were published in the last 3 years.

5. Dougados M, van der Heijde D, Chen Y-C, Greenwald M, Drescher $\mathrm{E}$, Liu J, et al. Baricitinib in patients with inadequate response or intolerance to conventional synthetic DMARDs: results from the RA-BUILD study. Ann Rheum Dis. 2017;76:88-95.

6. Teitsma XM, Jacobs JWG, Welsing PMJ, de Jong PHP, Hazes JMW, Weel AEAM, et al. Inadequate response to treat-to-target methotrexate therapy in patients with new-onset rheumatoid arthritis: development and validation of clinical predictors. Ann Rheum Dis. 2018;77:1261-7.

7. Ajeganova S, Huizinga T. Sustained remission in rheumatoid arthritis: latest evidence and clinical considerations. Ther Adv Musculoskelet Dis. 2017;9:249-62.

8. Liberati A, Altman DG, Tetzlaff J, Mulrow C, Gotzsche PC, Ioannidis JPA, et al. The PRISMA statement for reporting systematic reviews and meta-analyses of studies that evaluate healthcare interventions : explanation and elaboration. BMJ. 2009;339:b2700.

9. Higgins JPT, Altman DG, Gøtzsche PC, et al. The Cochrane Collaboration's tool for assessing risk of bias in randomised trials. BMJ. 2011;343:1-9.

10. Higgins JPT, Green S. Cochrane Handbook for Systematic Reviews of Interventions The Cochrane Collaboration, 2011; 2011. Available from www.handbook.cochrane.org.

11. Atsumi T, Yamamoto K, Takeuchi T, Yamanaka H, Ishiguro N, Tanaka Y, et al. The first double-blind, randomised, parallel-group certolizumab pegol study in methotrexate-naive early rheumatoid arthritis patients with poor prognostic factors, C-OPERA, shows inhibition of radiographic progression. Ann Rheum Dis. 2016;75:75-83.

12.• Burmester GR, Rigby WF, van Vollenhoven RF, et al. Tocilizumab in early progressive rheumatoid arthritis: FUNCTION, a randomised controlled trial. Ann Rheum Dis. 2016;75:1081-91 These studies are important because they were double-blind randomized controlled trials with a large sample size. The studies were powered to detect statistical significant differences. Besides, the articles were published in the last 3 years.

13. Dougados MR, van der Heijde DM, Brault Y, Koenig AS, Logeart IS. When to adjust therapy in patients with rheumatoid arthritis after initiation of etanercept plus methotrexate or methotrexate alone: findings from a randomized study (COMET). J Rheumatol. 2014;41:1922-34.

14.• Emery P, Bingham CO 3rd, Burmester GR, et al. Certolizumab pegol in combination with dose-optimised methotrexate in DMARD-naïve patients with early, active rheumatoid arthritis with poor prognostic factors: 1-year results from C-EARLY, a randomised, double-blind, placebo-controlled phase III study. Ann Rheum Dis. 2017;76:96-104 These studies are important because they were double-blind randomized controlled trials with a large sample size. The studies were powered to detect statistical significant differences. Besides, the articles were published in the last 3 years.

15. Horslev-Petersen K, Hetland ML, Junker P, et al. Adalimumab added to a treat-to-target strategy with methotrexate and intra-articular triamcinolone in early rheumatoid arthritis increased remission rates, function and quality of life. The OPERA Study: an investigator-initiated, randomised, double-blind. Ann Rheum Dis. 2014;73:654-61. 
16. Keystone EC, Dougados M, Ruderman EM, et al. Time to achieve moderate/low disease activity and remission in RA patients on baricitinib compared to a dalimumab, methotrexate, and placebo[abstract]. Arthritis Rheumatol 2017;69(suppl 10).

17. Keystone EC, Breedveld FC, van der Heijde D, et al. Achieving comprehensive disease control in patients with early and established rheumatoid arthritis treated with adalimumab plus methotrexate versus methotrexate alone. RMD Open. 2017;3: e000445.

18. Kirchgesner T, Vande Berg B, Sokolova T, et al. Evaluation of MRI RAMRIS score and clinical response in patients with ACPA positive undifferentiated arthritistreated with infliximab versus placebo. Ann Rheum Dis. 2018;77:1764.

19. Nam JL, Villeneuve E, Hensor EMA, Wakefield RJ, Conaghan PG, Green MJ, et al. A randomised controlled trial of etanercept and methotrexate to induce remission in early inflammatory arthritis: the EMPIRE trial. Ann Rheum Dis. 2014;73:1027-36.

20. Smolen JS, Wollenhaupt J, Gomez-Reino JJ, Grassi W, Gaillez C, Poncet $\mathrm{C}$, et al. Attainment and characteristics of clinical remission according to the new ACR-EULAR criteria in abatacept-treated patients with early rheumatoid arthritis: new analyses from the Abatacept study to gauge remission and joint damage progression in methotrexate (MTX)-naive patients with Early E rosive rheumatoid arthritis (AGREE). Arthritis Res Ther. 2015;17:157.

21. Stamm TA, Machold KP, Aletaha D, Alasti F, Lipsky P, Pisetsky D, et al. Induction of sustained remission in early inflammatory arthritis with the combination of infliximab plus methotrexate: the DINORA trial. Arthritis Res Ther. 2018;20:174.

22. Takeuchi T, Yamanaka H, Ishiguro N, Miyasaka N, Mukai M, Matsubara T, et al. Adalimumab, a human anti-TNF monoclonal antibody, outcome study for the prevention of joint damage in Japanese patients with early rheumatoid arthritis: the HOPEFUL 1 study. Ann Rheum Dis. 2014;73:536-43.

23. Brunekreef T, Bernelot Moens H. Remission induction with methotrexate step-up therapy versus combination of hydroxychloroquine, methotrexate and triamcinolone: 3 year results. Ann Rheum Dis. 2017;76:147-8.

24. Ma MHY, Scott IC, Dahanayake C, Cope AP, Scott DL. Clinical and serological predictors of remission in rheumatoid arthritis are dependent on treatment regimen. J Rheumatol. 2014;41:1298-303.

25. Rannio T, Asikainen J, Hannonen P, Yli-Kerttula T, Ekman P, Pirilä $\mathrm{L}$, et al. Three out of four disease-modifying anti-rheumatic drugnaïve rheumatoid arthritis patients meet 28 -joint disease activity score remission at 12 months: results from the FIN-ERA cohort. Scand J Rheumatol. 2017;46:425-31.

26. Steunebrink LMM, Versteeg GA, Vonkeman HE, ten Klooster PM, Kuper HH, Zijlstra TR, et al. Initial combination therapy versus step-up therapy in treatment to the target of remission in daily clinical practice in early rheumatoid arthritis patients: results from the DREAM registry. Arthritis Res Ther. 2016;18:60.

27. Akdemir G, Markusse IM, Bergstra SA, Goekoop RJ, Molenaar ET, van Groenendael JHLM, Kerstens PJSM, Lems WF, Huizinga TWJ, Allaart CF Comparison between low disease activity or das remission as treatment target in patients with early active rheumatoid arthritis. RMD Open 2018;4:e00649.

28. de Jong PH, Hazes JM, Han HK, Huisman M, van Zeben D, van der Lubbe PA, et al. Randomised comparison of initial triple DMARD therapy with methotrexate monotherapy in combination with lowdose glucocorticoid bridging therapy; 1-year data of the tREACH trial. Ann Rheum Dis. 2014;73:1331-9.

29. Nam JL, Villeneuve E, Hensor EMA, Conaghan PG, Keen HI, Buch $\mathrm{MH}$, et al. Remission induction comparing infliximab and high-dose intravenous steroid, followed by treat-to-target: a double-blind, randomised, controlled trial in new-onset, treatment-naive, rheumatoid arthritis (the IDEA study). Ann Rheum Dis. 2014;73:75-85.
30. Stouten V, Joly J, De Cock D, et al. Sustained effectiveness of methotrexate with step-down glucocorticoid remission induction (cobra slim) for early rheumatoid arthritis in a treat-to-target setting: 2-year results of the carera trial. Ann Rheum Dis. 2017;76:147.

31. ter Wee MM, den Uyl D, Boers M, et al. Intensive combination treatment regimens, including prednisolone, are effective in treating patients with early rheumatoid arthritis regardless of additional etanercept: 1year results of the COBRA-light open-label, randomised, noninferiority trial. Ann Rheum Dis. 2015;74:1233-40.

32. Verschueren P, De Cock D, Corluy L, et al. Effectiveness of methotrexate with step-down glucocorticoid remission induction (COBRA Slim) versus other intensive treatment strategies for early rheumatoid arthritis in a treat-to-target approach: 1-year results of CareRA, a randomised pragmatic open-la. Ann Rheum Dis. 2017;76:511-20.

33. Bergstra AS, Landewé RB, Huizinga TW, Allaart CF. Rheumatoid arthritis patients with continued low disease activity have similar outcomes over 10 years, regardless of initial therapy. Ann Rheum Dis. 2017;76:160.

34. Emery P, Fleischmann RM, Strusberg I, Durez P, Nash P, Amante EJB, et al. Efficacy and safety of subcutaneous golimumab in methotrexatenaive patients with rheumatoid arthritis: five-year results of a randomized clinical trial. Arthritis Care Res. 2016;68:744-52.

35. Keystone EC, Breedveld FC, van der Heijde D, Landewé R, Florentinus S, Arulmani U, et al. Longterm effect of delaying combination therapy with tumor necrosis factor inhibitor in patients with aggressive early rheumatoid arthritis: 10-year efficacy and safety of adalimumab from the randomized controlled PREMIER trial with open-label extension. J Rheumatol. 2014;41:5-14.

36. Konijn NPC, van Tuyl LHD, Boers M, den Uyl D, ter Wee MM, van der Wijden LKM, et al. Similar efficacy and safety of initial COBRA-light and COBRA therapy in rheumatoid arthritis: 4-year results from the COBRA-light trial. Rheumatol. 2017;56:1586-96.

37. Markusse IM, Akdemir G, Dirven L, Goekoop-Ruiterman YPM, van Groenendael JHLM, Han KH, et al. Long-term outcomes of patients with recent-onset rheumatoid arthritis after 10 years of tight controlled treatment: a randomized trial. Ann Intern Med. 2016;164:523-31

38. Verhoeven M, de Hair MJH, Welsing PMJ, et al. U-act-early trial 3 years follow-up. The longer effectiveness of treat-to-target strategies in early RA with tocilizumab, methotrexate, or their combination. Ann Rheum Dis. 2018;77:560.

39. van Nies JAB, Tsonaka R, Gaujoux-Viala C, Fautrel B, van der Helm-van Mil AHM. Evaluating relationships between symptom duration and persistence of rheumatoid arthritis: does a window of opportunity exist? Results on the Leiden early arthritis clinic and ESPOIR cohorts. Ann Rheum Dis. 2015;74:806-12.

40. Singh JA, Hossain A, Mudano AS, et al. Biologics or tofacitinib for people with rheumatoid arthritis naive to methotrexate: a systematic review and network meta-analysis. Cochrane Database Syst Rev. 2017;2017:CD012657.

41. Teitsma XM, Jacobs JWG, Welsing PMJ, Pethö-Schramm A, Borm MEA, van Laar JM, et al. Radiographic joint damage in early rheumatoid arthritis patients: comparing tocilizumab- and methotrexatebased treat-to-target strategies. Rheumatol. 2018;57:309-17.

42. Steunebrink LMM, Versteeg LGA, Vonkeman HE, ten Klooster PM, Hoekstra M, van de Laar MAFJ. Radiographic progression in early rheumatoid arthritis patients following initial combination versus step-up treat-to-target therapy in daily clinical practice: results from the DREAM registry. BMC Rheumatol. 2018;2:1-10.

Publisher's Note Springer Nature remains neutral with regard to jurisdictional claims in published maps and institutional affiliations. 